\title{
La Obra del Real Cuerpo de Ingenieros en las Fortalezas de Portobelo y de La Boca del Chagres en el siglo XVIII.
}

\author{
Leonardo Casini ${ }^{1,3, *}$ y Patricia Cid ${ }^{2,3}$ \\ ${ }^{1}$ Investigador Asociado, Universidad Católica Santa María la Antigua de Panamá. \\ ${ }^{2}$ Profesora e Investigadora, Facultad de Arquitectura y Diseño, Universidad Católica Santa María la Antigua de \\ Panamá \\ 3 Egresado/a de la Maestría en Restauración Arquitectónica, Università degli Studi Roma Tre, Italia. \\ * Autor para correspondencia. Email: 1.casini@casinicidarchitetti.it
}

Recibido: 04 de julio de 2017

Aceptado: 01 de agosto de 2017

\begin{abstract}
The defensive works of Portobelo and Chagre on the Caribbean coast of Panama represent an important testimony of the application in the New World of models of fortifications developed in Europe between the sixteenth and eighteenth centuries.
\end{abstract}

The fortifications of Panama were designed by the Italian engineer Battista Antonelli at the end of the 16th century, within the framework of a comprehensive regional defense strategic plan for the Caribbean area. The works that were executed are among the first applications in America of the typology of the "Fortificazione alla Moderna", as well as, they were developed in Italy and later, perfected in the European war theater. After the English attack carried out by admiral Vernon in 1740, the Spanish Crown decides to proceed to a new and detailed plan of redefinition of sites that will have in the work, mainly with the engineers of the "Real Cuerpo de Ingenieros", Ignacio Sala and Manuel Hernández, who will update the sites of Portobello and Chagre according to the new models developed in France in the late 17th century by Vauban.

The comparison of the adopted solutions allows to observe the evolution of the models of fortifications within a temporal arc of time of almost one hundred and fifty years. At the same time, the analysis of the projective and constructive events allows to traverse the development of the figure of the military engineer in Spain and the evolution of its cultural and formative background culminating with the foundation of the "Real Cuerpo de Ingenieros" in 1711 and the "Real Academia Militar de Matemáticas de Barcelona".

Keywords. Military Academies; Architectural Heritage; Military Engineering; Defensive Constructions; Real Cuerpo de Ingenieros. 


\section{Resumen}

Las obras defensivas de Portobelo y del Chagre en la costa caribeña panameña representan un testimonio importante sobre la aplicación en el Nuevo Mundo, de modelos de fortificaciones desarrolladas en Europa entre los siglos XVI y XVIII.

Las fortificaciones de Panamá fueron proyectadas por el ingeniero italiano Battista Antonelli a finales del siglo XVI, en el ámbito de un amplio plan estratégico de defensa regional para el área del Caribe. Las obras que se ejecutaron están entre las primeras aplicaciones en América de la tipología de la "Fortificazione alla Moderna”, así como, se realizaron en Italia y seguidamente, se perfeccionaron en el teatro bélico Europeo. Después del ataque inglés llevado a cabo por el almirante Vernon en 1740, la Corona Española decide proceder a un nuevo y detallado plan de redefinición de sitios que contará en la obra, principalmente, con los ingenieros del Real Cuerpo de Ingenieros, Ignacio Sala y Manuel Hernández, quienes actualizarán los sitios de Portobelo y el Chagre de acuerdo con los nuevos modelos planteados en Francia a finales del siglo XVII, por Vauban.

La comparación de las soluciones adoptadas permite observar la evolución de los modelos de fortificaciones dentro de un lapso de tiempo de casi ciento cincuenta años. En paralelo, el análisis de los acontecimientos proyectuales y constructivos permiten recorrer el crecimiento de la figura del ingeniero militar en España y la evolución de su retrotierra cultural y formativo que culmina con la fundación del "Real Cuerpo de Ingenieros” en 1711 y de la "Real Academia Militar de Matemáticas de Barcelona”.

Palabras clave. Academias Militares; Patrimonio Arquitectónico; Ingeniería Militar; Construcciones Defensivas; Real Cuerpo de Ingenieros.

\section{Introducción}

Las fortificaciones de Portobelo y de la boca del Chagre en Panamá forman parte de un plano más amplio de protección, gestión y defensa territorial que España adopta en los territorios de América, a partir de finales del Mil Quinientos.

Estas construcciones, además de, ser la representación plástica de una estrategia geopolítica, son el testimonio local del desarrollo de la cultura de la ingeniería europea que se da entre los siglos XVI y XVIII en el campo de las fortificaciones y donde los modelos, se aplican y se adaptan incluso en el Nuevo Mundo. 
Invest. pens. crit. (ISSN 1812-3864)

Vol. 5, No. 2, mayo-agosto 2017

pp. $83-109$

En este artículo, se analiza el contexto de la ingeniería de matriz europea que se convierte en escenario de las construcciones de las fortificaciones en la costa caribeña del Istmo de Panamá, durante la segunda mitad del siglo XVIII.

\section{Las Fortificaciones de Portobelo y De La Boca del Chagre. Siglos XVI - XVIII}

El Caribe se constituye desde el curso de la primera parte del Mil Quinientos como un nuevo frente donde se comparan las potencias antagonistas europeas. Si, en un primer momento, el control de la amenaza representada por los nativos había requerido un esfuerzo relativamente contenido, el enfrentamiento con los Ingleses, Franceses, Holandeses y las brigadas piráticas, en cambio, le exigen a España un empeño progresivamente más fuerte y tecnológicamente análogo a lo dispuesto en el Viejo Continente, con la variación de la disimetría para este nuevo teatro bélico.

En efecto, si por un lado, España intenta desde el principio establecer su presencia en América dirigida a la colonización y a la explotación de los nuevos territorios; por otro lado, las potencias hostiles, al menos hasta finales del siglo XVII, eligen crear sólo bases desde donde partir con las naves hacia el asalto de puertos y flotas españolas, siguiendo una estrategia inminentemente ofensiva aprobada para el ataque y el disturbio.

Bajo Felipe II, se elabora un complejo plan de defensa y ordenamiento territorial a escala regional que prevé la fortificación de puertos y de otros puntos sensibles en el escenario caribeño completo los cuales, se reconfirman como un cruce de conexión fundamental entre la península ibérica y el entero continente americano. El plan es supervisado en España, por el ingeniero italiano Tiburzio Spannocchi en calidad de "superintendente de ingenieros del rey"; por la parte militar, por Juan de Tejada; y por la parte de la ingeniería, por otro ingeniero italiano, Battista Antonelli, al que le seguirán, su sobrino Cristoforo Rota y su hijo, Juan Bautista Antonelli. En la Real Cédula emitida en Valencia, el 15 de febrero de 1586, donde se indican las figuras responsables, se resumen los detalles del plan:

"Por cuanto conviniendo á mi servicio y buena guarda y seguridad de las costas de las Indias [...] y del trato y comercio y seguridad de las flotas que van á las dichas Indias y vienen dellas, he acordado que se hagan y fabriquen los fuertes, torres y atalayas necesarias en las partes y lugares mas cómodos y apropósito que parecieren convenir a ver y visitar las dichas costas y reconocer y tomar relación de las dichas partes en que se deben hacer y edificar, y disposiciones de ellas y de lo demas para su edificio y fortificacion se deba bacer y prevenir, he nombrado á Juan de Tejada, como persona plática y de experiencia en las cosas de la guerra, [...] é porque mejor se haga mi servicio y lo que conviniere cerca de los dichos sitios y partes donde se hayan de hacer los dichos fuertes y torres é atalayas, trazas é modelo dellas, conviene vaya con él una persona, que sea ingeniero y de práctica y experiencia en semejante ministerio, teniendo satisfacción de vos Baptista Antonelli, y de la mucha que teneis de cosas de fortificaciones, y 
Invest. pens. crit. (ISSN 1812-3864)

Vol. 5, No. 2, mayo-agosto 2017

pp. 83-109

acatando lo que he habeis servido en otras muchas, os he querido nombrar, como por la presente os nombro por mi ingeniero para el dicho defecto [... $]^{\text {"1 }}$.

El plan resulta fundamental para la definición de la organización del sub-sistema integrado de las tres "llaves" de Portobelo, la Boca del Chagres y la ciudad de Panamá en su posición original, y redefine el percurso de conexión terrestre entre los ricos territorios de la costa del Pacífico, del Caribe y por tanto, de España, constituyendo la matriz donde se establecerán las intervenciones de los siglos a seguir. Antonelli, ya en 1587, indica el costo para la construcción de un presidio fortificado en la Boca del Chagres:

"[...]La torre de la boca del río Chagre costará como siete mil seiscientos ochenta y cinco ducados, y esto será conforme á la grandaria que bubiere de tener [... ]" 2

La obra será realizada en 1595. Por otro lado, también en 1587, escribe al Rey en relación a la posibilidad y conveniencia de trasladar a la comunidad de colonos de Nombre de Dios a Portobelo, detallando las ventajas:

"[...] fuimos á ver á Portobelo, y es un grande y capazpara muchas armadas, y abrigado de todos los vientos, que en esta costa suelen ofender [...].Tiene este puerto cuatro cosas que son las que requiere un buen puerto. La primera tiene mucho fondo el puerto limpio, y piedra para lastre y agua para hacer aguada, y mucha madera asi para el servicio de la poblacion, como para fabricar navios; y de todas estas cosas carescen mucho los puertos, y particularmente los de esta costa. Y si S. M. mandase se pasase la poblacion de Nombre de Dios á aqui, [...]. Tambien la entrada del puerto, si S. M. fuese servido, se podria fortificar teniendo tan buena disposicion como tiene. De la parte del mediodia se podría hacer un fortezuelo, y de la otra banda una torre, de esta manera estaria seguro el puerto y los vecinos; [... ]” 3 .

En 1597 se trasladada la comunidad de Portobelo, el 11 de septiembre se coloca la primera piedra del Fuerte San Felipe y en 1600, se inicia la construcción del Fuerte Santiago de la Gloria ${ }^{4}$.

\section{Las Academias y el Real Cuerpo de Ingenieros}

Hacia finales del Mil Quinientos, el tema de la actualización de las defensas según los dictámenes de la "fortificazione alla moderna" pone en evidencia la necesidad tanto para España, como para otras potencias europeas, de disponer de un número congruo de técnicos adecuadamente especializados en este sector específico. En esta época, efectivamente, los técnicos de origen italiana poseen casi por completo, el

\footnotetext{
1 "Real cédula por la que el Rey nombra á Antonelli su ingeniero para que vaya á examinar las costas y puntos de América, donde convenga levantar fuertes y castillos. 15 febbraio 1585." Transcripción por (Llanuro y Amirola, y otros, 1829).

2 "Memoria de lo que costará el fortificar el puerto de Cartagena, Puertobelo, río de Chagre, las casas reales de Panamá y el Morro de La Habana, hecha por Baptista Antonelli. 1587." Transcripción por (Llanuro y Amirola, y otros, 1829).

${ }^{3}$ Capítulos de una carta que Antonelli escribió al duque de Medinasidonia, desde Cartagena de Indias. 14 de diciembre de 1586. Transcripción por (Llanuro y Amirola, y otros, 1829).

${ }^{4}$ Sobre los aspectos constructivos de Santiago de la Gloria y la realización de un primer caballero con una plataforma anexa, ver (Castillero Calvo, 2016).
} 
Invest. pens. crit. (ISSN 1812-3864)

Vol. 5, No. 2, mayo-agosto 2017

pp. 83-109

monopolio en la teorización, proyectación y realización de estos complejos y costosas obras bélicas, y sus servicios son requeridos en las principales cortes del continente ${ }^{5}$.

La necesidad de formar una reserva local propia de técnicos, se convierte en una condición fundamental para las ambiciones de una Potencia que desea jugar como protagonista en un escenario donde el horizonte se ha expandido a escala intercontinental y donde la competencia de los estados hostiles es siempre más preparada. Por esta razón, en 1582 y bajo Felipe II, se crea La Academia Real Ma-thematica de Madrid a solicitud de Juan de Herrera y con la colaboración de Tiburzio Spannocchi. El propósito primordial de esta Academia era la de preparar un número adecuado de técnicos españoles que pudiesen ser útiles al Estado y que tuviesen una formación sólida y apropiada sobre una base científica.

" [...] ay falta en la república de artifices entendidos y perfectos para muchos usos y ministerios necesarios a la vida politica $[\ldots]^{\prime \prime}$.

Herrera centra la Academia en las disciplinas matemáticas, ya que, las considera fundamentales para acceder a otros conocimientos porque "[...] abren la entrada y puerta a todas las demás scincias por su gran certitud y mucha evidencia [...]” y entre las varias disciplinas que de ésta derivan, indica que la Mechànica de la cual, "[...] depende la hazedora de instrumentos bèllicos para opugnar y deffender las ciudades y fortalezas [...] "y "[...] la Architectura y Arte de fäbricas y de fortificaciones, que plantean los alarifes, los arqueadores de navios, niveladores de aguas, ingenieros, artilleros, fundidores y otros artifices muchos, que usan estas divinas Mathemàticas por beneficio y miedo de quantidad continua o discreta [...]”".

La lista de los técnicos a los cuales, se orientaba la Academia para formarles y perfeccionarles sus conocimientos es ilustrativa del esfuerzo y de las ambiciones de la España de Felipe II.

" [...] Geómetras diestros en el medir todo género de superficies [...] Cosmógrafos scientificos para situar las tierras, y descriuir las pronincias y regiones, Pilotos diestros y cursados en navegaciones que sepan guiar con seguridad las flotas y poderosas armadas [...] Architectos y fortificadores fundados que con fábricas magníficas, y edificios públicos, y particulares ennoblezcan las ciudades, y las fortifiquen y defiendan asegurándolas del impetu de los enemigos. Ingenieros y Machinistas, entendidos en la arte de los pesos, fundamento para hazer y entender todo género de Machinas, de que la vida política y Económica se sirve. Artilleros y maestros de instrumentos y aparatos béllicos [...] Y asi mismo fontaneros y nivelado es de las aguas para los aguaductos y regadios... Y para desaguar y beneficiar las minas de ricos metales [...]"

A partir del 1591, la Academia pasa significativamente a depender del Consejo de Indias. En 1595, Felipe II nombra como docente de Matemáticas al ingeniero milanés, Giuliano Ferrofino, quien enfoca las enseñanzas de manera más pronunciada, en las temáticas de las Fortificaciones y de la Artillería gracias al apoyo del Conde de Puñoenrostro, General de la Artillería y máximo responsable de ella en el Consejo de Guerra, que apoyó para que se impartieran esas nuevas materias relacionadas con el arte y la ingeniería

\footnotetext{
5 (Casini L., Cid P. , 2016).

"Juan de Herrera, "Institución de la Academia Real de Mathemàtica” 1584.
} 
Invest. pens. crit. (ISSN 1812-3864)

Vol. 5, No. 2, mayo-agosto 2017

pp. 83-109

militar $^{7}$. De este modo, se introducen algunos cursos específicos. Ferrofino enseñará Artillería, mientras que, el capitán e ingeniero Cristóbal de Rojas, se ocupará del tema de las fortificaciones siguiendo su propio tratado "Tratado y práctica de fortificación, conforme a las medidas y defensas destos tiempos" 8 , curso que tendrá hasta su transferencia a Cadiz, en 1596.

La Academia, a lo largo de su actividad que prosigue por más de 40 años con alguna discontinuidad, logra sólo parcialmente honrar los objetivos preestablecidos. Si, por una parte, es innegable que se mantenga siempre un alto perfil de los docentes que permita la circulación de las obras de los principales autores europeos de la época y la producción de contributos originales en las diversas disciplinas; por otra, no se institucionaliza la formación de conocimientos técnicos deseada por Herrera, ni se forman los técnicos calificados requeridos.

La Academia, en efecto, repite el planteamiento de las "escuelas de palacio" donde se educan los cortesanos y los hijos de la nobleza, si bien, con las novedades fundamentales de la enseñanza de materias prácticas y de una mayor abertura, relativamente a la época, hacia una categoría social más amplia. Aún así, no llega a configurarse como un centro estructurado de formación, ya que, no se realizaban exámenes, no se otorgaban títulos y la participación era sólo como oyentes. El único curso que se mantiene bajo una cierta regularidad es el de Cosmografía, mientras que, los cursos relativos a las Fortificaciones y la Artillería cuentan con una tendencia discontinua y de poca duración.

En 1675, se abre en Bruselas, la Academia Real y Militar del Ejército de los Países Bajos con el objetivo de dirigir y uniformar la educación de los ingenieros militares encuadrados en el ejército a través de una base científica adecuada. El frente de los Países Bajos representa uno de los teatros bélicos más difíciles para la Corona Española desde finales del siglo XVI hasta inicios del XVIII. En el campo de la artillería y de las fortificaciones, y a causa del constante estado de conflicto y movilización, esta región representa uno de los escenarios más importantes de aplicación, perfeccionamiento y empleo de los preceptos de las "fortificaciones a la moderna".

Así como en Italia a inicios del Mil Quinientos, la necesidad concreta de proveer a las defensas de las ciudades y a la construcción de plazasfuertes equipadas hace que se desarrollen en el área, originales declinaciones locales de los modelos del frente bastionado con la evolución de nuevas tipologías y soluciones aplicativas que seguirán las orientaciones de una "escuela holandesa" y de una "escuela francesa" de las fortificaciones, que recogen el testimonio de la "escuela italiana" de origen. Para los ingenieros militares al servicio de los Países Bajos será una ocasión importante y de práctica profesional que, inmediatamente, representan y magnifican como una etapa fundamental de su propio cursus honorum.

La Academia de Bruselas localizada significativamente en esta área así importante para las temáticas de estudio, fue plasmada por su único director, Sebastián Fernández de Medrano, quien la dirigió hasta el año de su muerte. Los alumnos provenían de las filas del ejército y seguían por un año, cursos en las

\footnotetext{
${ }^{7}$ (Piñeiro, 2002).

8 Primer tratado impreso de un ingeniero español. Publicado en 1598.
} 
Invest. pens. crit. (ISSN 1812-3864)

Vol. 5, No. 2, mayo-agosto 2017

pp. 83-109

disciplinas de Geometría, Artillería, Fortificación, Arte de “escuadornar” y Geografía. Al término de este período, la mayor parte regresaba a sus propios repartos donde instruían a sus colegas en lo adquirido. Los mejores, en cambio, se quedaban por un año más, profundizando y completando su formación con nuevos cursos. Después de este período, los más preparados completaban sus estudios en un regimiento y podían ser llamados a cumplir algunos deberes particulares, con el grado de "ingeniero extraordinario". El sucesivo grado de "ingeniero ordinario", difícil de conseguir, podía ser obtenido sólo pasando un examen con otro ingeniero. Al culminar los estudios, se emitía un certificado.

La urgencia bélica de formar rápidamente personal para emplear en la guerra, probablemente, bajó el tenor de las enseñanzas, certificándolos por necesidad, en un nivel poco especializado. El mismo Medrano indica que en los 4000 estudiantes que pasaron por la Academia hasta 1704, advierte una necesaria simplicidad en algunos de sus escritos, proporcionando una indirecta confirmación de esta condición?. Cabe subrayar que la Academia produjo, por la mano del mismo Medrano, diversas publicaciones como material didáctico los cuales, se convirtieron en una de las referencias formativas para los ingenieros de la época. Sólo los títulos, ya son ejemplo de las enseñanzas que venían impartidas: "Rudimentos Geométricos y Militares" (1677); "El Práctico Artillero" (1691); "El Ingeniero Práctico" (Bruselas, 1696); "El Arquitecto Perfecto en el Arte Militar" (Amberes, 1708); "Elementos de Euclides amplificados"; "Geografía Moderna, descripción del Mundo y sus Partes" (Amberes,1719); "Fundación y Reglas de la Academia llamada la Peregrina".

El tema de la formación de los ingenieros militares sumado a la cuestión de su encuadramiento en un cuerpo independiente, se representa con carácter de necesidad al inicio del siglo XVIII. El contexto histórico de fondo a esta iniciativa es aquel de la Guerra de Sucesión Española, que deriva del ingreso de la dinastía Borbón en el trono de España y la redefinición continental de los equilibrios con la Alianza entre Francia y España. En este marco, se presenta la imperante necesidad de reponer los rangos de los ingenieros militares diezmados por el conflicto que, en un primer momento, incluso debe ser satisfecha a través de la incorporación de una brigada de ingenieros franceses que Luis XIV envía en España, por petición de Felipe V.

Para evitar esta situación, se pone mano a una reorganización general del sector a través de la instauración del Real Cuerpo de Ingenieros, con el propósito de crear una estructura jerarquizada e independiente que fuese plenamente operativa según un modelo que retomase, con las debidas diferencias dadas por el contexto y la organización territorial, el modelo del "Département des fortifications des places de terre et de mer" establecido por el mismo Luis XIV, en 1691. Cada vez se hace más fuerte, el reconocer que un cuerpo de ingenieros bien organizado, además de necesario, era también un instrumento válido para la organización y el control estratégico del Estado, tanto en el campo civil, como en el militar. Hay que resaltar, por otro lado, que la presencia de un soberano Borbón en el trono de España, permite compartir las experiencias en el campo de las fortificaciones de los ingenieros franceses, herederos de las enseñanzas del Marqués de Vauban, reconocido entre los máximos ingenieros militares de la época.

\footnotetext{
${ }^{9}$ (Capel, y otros, 1988).
} 
Invest. pens. crit. (ISSN 1812-3864)

Vol. 5, No. 2, mayo-agosto 2017

pp. $83-109$

Hasta aquel tiempo, la figura del ingeniero militar no había sido todavía, plenamente encuadrada dentro de un cuerpo militar en sí, sino que era considerado en el ejército de acuerdo con las necesidades operativas, entre la infantería y la artillería. Incluso, la formación no había sido todavía organizada de manera unívoca, ya que, aún convivían las posibilidades de formarse en el campo como discípulo de otro ingeniero con mayor experiencia o de la Academia.

Para organizar el Real Cuerpo de Ingenieros, se llama a Jorge Próspero Verboom ${ }^{10}$, prestigioso ingeniero militar que se había formado en la Academia de Bruselas donde había sido asistente del mismo Medrano. Nombrado en 1710, por Felipe V como Ingeniero General ${ }^{11}$ y Cuartel Maestre General ${ }^{12}$, para el 4 de julio del mismo año, dirige un memorial ${ }^{13}$ al Marqués de Bedmar acerca de la formación de un cuerpo de ingenieros en el cual, extiende una primera propuesta de reglamento, entre ellas ${ }^{14}$, la necesidad de considerar sus propios grados para encuadrar al cuerpo y para obtener el correcto reconocimiento por sus profesionalidades:

" [...] sabe cuanto importa al Real servicio de establecer un Cuerpo de Ingenieros en este Reyno, que tanta falta ha hecho basta ahora [...] los ingenieros necesitan los grados, tanto para dar consideración a las funciones de su empleo, como para adelantarse, no siendo razón que este género de oficiales, que trabajan más y están más expuestos a los peligros de la guerra que cualesquiera otros, se hallen sin ellos [... ${ }^{\prime \prime}$

El 21 de abril de 1711, se promulga el Real Decreto ${ }^{15}$ donde se establecen los grados, los salarios y las raciones. Los eventos bélicos, ante todo, aquéllos relativos a la toma de Barcelona, retrasan la plena definición de la cuestión ${ }^{16}$ hasta la promulgación de la "Real Ordenanza e Instrucción de 4 de julio de 1718 para los Ingenieros", inspirada por el mismo Verboom y en donde en 62 artículos, se indican con precisión las tareas, con la finalidad de homogenizar y unificar en un único código, la producción de cada ingeniero.

\footnotetext{
${ }^{10}$ Su padre fue Cornelio Verboom, Ingeniero Mayor de los Países Bajos a finales del siglo XVII.

11 ".... Ingeniero general de mis ejércitos, plazas y fortificaciones de todos mis reinos, provincias y estados en cualesquier partes que sean y os halla reis [...]" Real Decreto de 13 de enero de 1710; Archivo de Simancas: Secretaría de Guerra Moderna.- Indiferente de Inge-n ieros.- Legajo núm. 3.799.- Año de 1710. En los documentos coleccionados por Aparici. Siglo XVIII.- Gobierno del Cuer-p o. Tomo I, folios 265 a 259. Citado por Joaquín de la Llave en su biografía de don Jorge Próspero de Verboom publicada e n el número de abril de 1911 del Memorial de Ingenieros. Tomo 66, páginas 124 a 126. Transcripción en (AA.VV., 2004). 12 “... Cuartel-maestre general de los ejércitos de todos los reinos [... ." Real Decreto de 13 de enero de 1710, Archivo de Simancas: S ecretaría de Guerra Moderna.- Indiferente de Ingenieros.- Legajo núm. 3.799.- Año de 1710. En los documentos coleccio-n ados por Aparici. Siglo XVIII.- Gobierno del Cuerpo. Tomo I, folios 265 a 259. Citado por Joaquín de la Llave en su bio-gr afía de don Jorge Próspero de Verboom publicada en el número de abril de 1911 del Memorial de Ingenieros. Tomo 66, pág inas 127 a 129. Transcripción en (AA.VV., 2004).

13 Archivo de Simancas, Negociado de Guerra Moderna, legajo 2998, año 1710. Colección Aparici: siglo XVIII, Tomo LIV, signatura 1-2-5, números 5.975 y 5.976. Transcripción en (AA.VV., 2004).

${ }^{14}$ Incluído el correcto salario " [...] considerando los peligros, travajos y gastos continuos a que están espuestos estos Oficiales, más que los ot ros; por lo cual se les ha de atender en los sueldos que convendría señalarlos en las Tesorerías, o otros receptas de las Rentas Reales en donde estubi esen pagados puntualmente, sin lo cual no será posible que puedan subsistir [...] ” ibíd.

15 Archivo de Simancas: Guerra Moderna.- Legajo núm. 2.991.- Año 1711. Citado por Joaquín de la Llave en su biografía de Próspero de Verboom en el número de abril de 1911 del Memorial del Arma de Ingenieros. Tomo 66, página 132.

${ }^{16} \mathrm{El}$ mismo Verboom es hecho prisionero por el enemigo.
} 
Invest. pens. crit. (ISSN 1812-3864)

Vol. 5, No. 2, mayo-agosto 2017

pp. 83-109

" [...] se trata de la formación de Mapas, o Cartas Geográficas de Provincias, con observaciones y notas sobre los Rios que se pudieren hacer navegables, Cequias para Molinos, Batanes, Riegos, y otras diversas diligencias dirigidas al beneficio universal de los Pueblos; y asimismo al reconocimiento y formación de Planos, y Relaciones de Plazas, Puertos de Mar, Babias, y Costas, y de los reparos, y nuevas obras que necesitaren, con el tanteo de su coste [...] se expresan los reconocimientos, tanteos y formalidades con que se han de proponer, determinar y executar los obras nuevas, y los reparos que fueren precios en las Fortificaciones, Almacenes, Quarteles, Muelles y otras Fábricas Reales, y sobre conservación de las Plazas, y Puertos de Mar"

Es, fundamental, subrayar que las tareas asignadas a los ingenieros militares, no se limitan sólo a los temas relativos a las fortalezas sino que, además, se extienden a un horizonte mucho más vasto que abraza también, a las tareas de la ingeniería civil. Esta universalidad que aquí se ve ratificada en forma oficial, era una prerrogativa que ya caracterizaba a la figura del ingeniero militar, basta indicar a título de ejemplo, a las obras de Giovanni Battista Antonelli para hacer navegable el río Tajo (desde Toledo a Lisboa) o la presa que construyó en Tibi (Alicante). Es interesante la anotación que sigue, ubicada en la premisa del documento y utilizada como justificación para hacer referencia a la mala gestión de algunos proyectos ${ }^{17}$ entre los cuales, se indican significativamente algunas fortalezas realizadas incluso, sin la dirección de profesionales adecuados.

"[...] y [Yo el Rey] hallandome bien informado de que en diversas ocasiones se han construido muchas Fortificaciones, y otras obras inútiles en las Plazas, y Puertos de Mary desperdiciadose en ellas considerables caudales de mi Real Hacienda, y de los Pueblos, por haberse executado sin planta, ni dirección de Ingenieros profesos de inteligencia [...] sin que proceda orden, ni proyecto aprobado por Mi, de que ha resultado también haberse hecho algunas muy defectuosas, y otras enteramente contrarias a la defensa de las mismas plazas, por lo qual ha sido preciso demolerlas, causando nuevos gastos, con gran detrimento de mi Hacienda [...] y deseando obviar en adelante estos, y otros inconvenientes, prescribiendo a los Ingenieros, y demás personas a quienes tocare, las reglas con que han de proceder en estas dos importancias, y atender a mi mayor servicio: he resuelto establecerlas en la forma que distintamente se explican en la Instrucción siguiente"

El proyecto de la institución del Cuerpo de Ingenieros, se completa con la creación de la Real Academia Militar de Matemáticas de Barcelona la cual, Verboom había iniciado a establecer ya en $1712^{18}$. Abierta en 1720 luego de, vicisitudes alternas ${ }^{19}$, es oficialmente ratificada por la Real Ordenanza del 22 de julio de 1739. El curso duraba tres años y se subdividía en cuatro "clases" donde las primeras dos correspondían a nociones generales para cualquier oficial del ejército, mientras que, las últimas dos estaban dirigidas específicamente a ingenieros y artilleros.

\footnotetext{
${ }^{17}$ La situación había sido ya planteada por Verboom en la Carta que envía al Marqués de Bedmar, el 4 de julio de 1712 cuan -do habla de "[...] las obras nuevas que se han hecho en Lérida, y aún las viejas se están cayendo por haber sido fabricadas por Oficiales nescio s, que no han sabido buscar el terreno sólido para establecer sus cimientos [...]".

${ }_{18}$ Citado en (AA.VV., 1983) "Projet pour une accademie, ou Ecole, ou se doit de montrer les mathematiques, Fortifcaitions, et Dessein, dans les parties qui conviennent de sçavoir à un officier de Guerre, et particuliérement pour ceux qui soubaiterontd'entrer dans le corps des Ingénieurs." ${ }^{19}$ Una Academia de Arquitectura Militar existía ya en Barcelona desde 1686 la cual, es cerrada por causa de la guerra. En 17 20, abre nuevamente una Academia con director a Matteo Calabro el cual, le seguirá en 1738, Pedro Lucuce.
} 
Invest. pens. crit. (ISSN 1812-3864)

Vol. 5, No. 2, mayo-agosto 2017

pp. 83-109

Inicialmente, a través de un examen previo, se seleccionaban 18 oficiales y 18 cadetes más 4 civiles, para un total de 40 unidades. La selección dentro de los rangos del ejército incluía aún a la infantería y a la artillería, y el percurso formativo todavía se realizaba en común. En la primera clase, se seguían cursos de Matemáticas, Geometría y Topografía; en la segunda, cursos de Artillería, Fortificación, Ataque y defensa de las plazas y Táctica; en la tercera, de Mecánica y máquinas, Hidráulica, Gnomónica, Perspectiva, Construcción y Formación y uso de cartas geográficas; y por último, en la cuarta, cursos de Dibujo y Proyectos de edificios civiles y militares. Para acceder a las "clases" sucesivas, se necesitaban aprobar los exámenes. Sólo quien completaba los cuatro años de estudio podía realizar un ulterior examen para ingresar al Real Cuerpo de Ingenieros o al Real Cuerpo de Artilleros presentándose, respectivamente, ante la Real Junta de Fortificaciones o ante la Real Junta de Artilleros.

La Academia de Barcelona de la cual, en 1751 se separa la formación de los Artilleros que, en cambio, prosigue a través de una Academia propia y expresamente dedicada a ellos, cerrará en 1803 con la apertura de la Academia de Ingenieros en Alcalá de Henares. La educación científica y técnica impartida en Barcelona era la más avanzada de la Península y superaban las impartidas en las Universidades. El alto perfil de las enseñanzas, se confirmaba también a través de la importancia de la Biblioteca de la Academia que contaba en 1790, con más de 20.000 volúmenes que comprendían, además de, las más importantes y reconocidas obras de la literatura técnica que circulaban en Europa en aquel período, las publicaciones redactadas por los mismos profesores de la Academia para sus cursos.

Además de la Academia de Barcelona, se instituyen bajo criterios similares, la Academia de Orán en 1732 y la de Ceuta en 1739, luego reformada en 1751, convirtiéndola en sede separada de Barcelona ${ }^{20}$. Estas Academias fueron transferidas, respectivamente, a Zamora y Cádiz, en 1789. El alto nivel de la educación impartida en estos centros de formación para el personal del Ejército, considerada como un conocimiento de naturaleza estratégica para la suerte del Estado, podría ser la raíz de las decisiones de la Corona en no abrir centros de enseñanzas en áreas demasiado lejanas de la península. En este sentido, es emblemático el caso del rechazo del proyecto del ingeniero Simón Desnaux, de abrir una "Academia especulativa y práctica sobre el arte de la guerra" en la Nueva España, basada en el modelo de la Academia de Barcelona. Además de, la indicada propensión a controlar la difusión de ciertos enseñamientos, se ha hecho notar ${ }^{21}$ que existiese también la voluntad de obstaculizar y contener la emancipación de la clase militar criolla que habría podido favorecerse abriendo centros de formación así avanzados.

Se tiene noticia además, de una Academia de Delineación con una cátedra de Matemática abierta en Cartagena de Indias por el ingeniero Juan de Herrera y Sotomayor, entre el 1725 y el 1732 22 , con el objetivo de formar en el lugar, un cierto número de técnicos ingenieros para satisfacer a la crónica carencia de profesionales en el territorio americano. Esta carencia, además de, las reticencias de orden

\footnotetext{
20 "Real Ordenanza de 29 de diciembre de 1751, para la Subsistencia, Régimen, y enseñanza de la Real Academia Militar de Matemáticas, est ablecida en Barcelona, y las particulares de Ceuta, y Orán, unas y otras al cargo y dirección del Cuerpo de Ingenieros, para la enseñanza de los ofi ciales, y cadetes del Ejército".

21 (Capel, y otros, 1988).

22 (Zapatero, 1985); (Gutiérrez, 2005); In (Capel, y otros, 1988) se reporta que la “Academia Militar de Matematicas Cartaginesas ”abre el 9 de abril de 1731 y cesa la actividad el 25 de febrero del 1732.
} 
Invest. pens. crit. (ISSN 1812-3864)

Vol. 5, No. 2, mayo-agosto 2017

pp. 83-109

"político" indicadas, se atribuyen a las objetivas dificultades que la destinación Americana presentaba con respecto, a las destinaciones europeas. Los largos viajes de traslados por vía marítima con los peligros relacionados, las asperezas del clima, los largos períodos de servicio en el orden de años lejanos de la madre patria, el estar en un área mas bien periférica respecto al Centro Decisional con las relativas limitaciones para el ascenso profesional en orden de importancia y grado y, no por último o menos importante, el sutil temor del predecible retraso en los pagos del salario, hacían que la destinación Americana fuera poco apetecible. No por nada, el ser soltero era uno de los principales requisitos del perfil del ingeniero escogido para desplazarse en estas áreas.

En un reporte del 1778, el Director de Ingenieros, Silvestre Abarca, escribe que entre América y Filipinas prestaban servicio 57 ingenieros en comparación con los 150 que estaban en España y evalúa que servirían al menos 88 , mientras que, el número ideal debería haber sido de $110^{23}$.

\section{Tab. 1 - Número de Ingenieros por año al servicio de la Corona Española ${ }^{24}$}

\begin{tabular}{c|c|c|c|c|c|c|c|c|c|c|c|c|c|c}
1501 & 1525 & 1550 & 1575 & 1625 & 1650 & 1675 & 1723 & 1728 & 1733 & 1739 & 1740 & 1765 & 1778 & 1803 \\
1524 & 1549 & 1574 & 1599 & 1649 & 1674 & 1699 & & & & & & & & \\
\hline 5 & 17 & 24 & 32 & 96 & 60 & 65 & 84 & 128 & 129 & 114 & 140 & 150 & 147 & 196
\end{tabular}

Tab. 2 - Ingenieros militares en América en el siglo XVIII ${ }^{25}$

\begin{tabular}{l|c|c|c|c} 
& $1700-1720$ & $1721-1768$ & $1769-1800$ & $1800-1808$ \\
\hline Colombia, Ecuador, Panamá y Venezuela & 2 & 32 & 29 & 7 \\
\hline Nueva España & 6 & 30 & 54 & 3 \\
\hline Cuba, Puerto Rico, Santo Domingo, Isla Trinidad & 5 & 27 & 29 & 4 \\
\hline Florida y Louisiana & 1 & 7 & 8 & 0 \\
\hline Guatemala, Costa Rica, Honduras y Nicaragua & 0 & 6 & 13 & 2 \\
\hline Argentina,Paraguay y Uruguay & 2 & 5 & 22 & 1 \\
\hline Chile y Perú & 1 & 11 & 22 & 3
\end{tabular}

23 (Capel, y otros, 1988).

24 (Muñoz Corbalán, 2015) y (Capel, y otros, 1988).

25Datos elaborados por José Omar Moncada Maya, Instituto de Geografía - Universidad Nacional Autónoma de México, en (Capel, y otros, 1988). 
Invest. pens. crit. (ISSN 1812-3864)

Vol. 5, No. 2, mayo-agosto 2017

pp. 83-109

\section{Las Fortificaciones de Portobelo y de San Lorenzo en el siglo XVIII}

Entre 1739 y 1740, durante la Guerra del Asiento, las fortificaciones de Portobelo y de la Boca del Chagres son atacadas y vueltas inoperativas por la escuadra naval inglesa comandada por el almirante Vernon. La orden de repristinar y adecuar las fortalezas destruidas junto a las de Cartagena de Indias ${ }^{26}$, es dada al Ingeniero don Ignacio Sala y Garrigó, nombrado con Real Cédula del 10 de noviembre de 1748 por el Rey Fernando VI, y como Gobernador y Comandante General dela Ciudad y Provincia de Cartagena de Indias ${ }^{27}$.

Sala es un exponente de primer plano del Real Cuerpo de Ingenieros. A inicios del Mil Setecientos, brinda servicio como ingeniero voluntario en Cataluña durante la Guerra de Sucesión y bajo Verboom, en las plazas de Barcelona y Lérida. Luego, al ascender de grado, concentrará su trabajo principalmente en Cádiz, donde participa en la realización de obras defensivas. Sala es autor de numerosas publicaciones ${ }^{28}$, entre ellas, el "Tratado de las defensas de las Plazas de M. Vauban, Mariscal de Francia, con algunas reflexiones y adiciones" ${ }^{29}$ del 1743, en donde reanuda y amplía los conceptos estratégicos del Marqués de Vauban cuyas aplicaciones en la realización de complejas obras defensivas y en la estrategia de ataque y defensa de las fortificaciones, hemos visto que, se encontraban como base de los cursos de las academias militares y de las prácticas de los ingenieros militares de la época.

Junto a Sala también se envía en América, al ingeniero Manuel Hernández, con el grado de segundo ingeniero. Hernández se había formado ${ }^{30}$ en la Real Academia de Barcelona y había brindado servicio por mucho tiempo en las Canarias donde es apreciada su obra de relieve y de proyectación de algunas de las defensas del archipiélago ${ }^{31}$. Mientras que, como ayudante de Hernández y coordinador de algunas construcciones encontramos a José Antonio Brist, quien inicia con el grado de ingeniero extraordinario.

Algunos años más tarde, cuando se agudizan nuevamente las tensiones entre España e Inglaterra, se envía al ingeniero Agustín Crame para un extenso y exhaustivo reconocimiento de las defensas del área completa del Caribe, quien estará presente en Portobelo y en San Lorenzo en 1779. Nacido en Navarra en 1730, ingresa al Real Cuerpo de Ingenieros en 1750 y se convierte en profesor de la Real Academia de Matemática de Barcelona ${ }^{32}$ en 1760. Para 1775, es designado como "Visitador General de las Fortificaciones de América" con una serie de encargos que se describen en una carta de 1776 redactada por el Conde O’Railly, donde se especifica que deberá realizar una rendición de cuentas de las áreas, las fortificaciones

\footnotetext{
${ }^{26}$ Cartagena de Indias asediada por Vernon en 1741, a pesar de sufrir graves pérdidas, logró resistir al ataque inglés.

${ }^{27} \mathrm{El}$ prestigioso título es dado por primera vez a un ingeniero (Freire, 2013).

28 "Apuntes sobre la línea de Gibraltar" 1742, "Informe sobre el muelle de Málaga" 1743, "Tratado de seguridad y conservación del Estado p or medio de las fortalezas..." 1746 (Freire, 2013).

${ }^{29} \mathrm{El}$ argumento de este tratado es de naturaleza estratégica y examina los procedimientos de ataque y defensa de una Plaza y a construida. En particular, se centra en los procedimientos de defensa que el Gobernador de Plaza debe seguir.

${ }^{30}$ Una ficha biográfica completa, se aprecia en (Melià, 2014).

31 (Melià, 2014) y (García, 2003).

32 (Arcos Martínez, 2016).
} 
Invest. pens. crit. (ISSN 1812-3864)

Vol. 5, No. 2, mayo-agosto 2017

pp. 83-109

y de los armamentos, "[...]reconocer las inmediaciones de dichas plazas y formar el plan de defensa, [...]. Seguirá un reconocimiento exacto de la misma plaza, para proponer las obras que fueren precisas para su defensa [... ." ${ }^{33}$.

\subsection{Portobelo}

En 1752, Sala se encuentra en Portobelo después de haber participado en la reorganización de las defensas de Cartagena. De acuerdo con la praxis operativa, como ya indicada en la "Real Ordenanza e Instrucción de 4 de julio de 1718 para los Ingenieros", la primera fase consiste en el levantamiento métrico del estado actual de las fortalezas y de las conformaciones del sitio, deber del cual se ocupó Hernández.

Esta fase de adquisición de conocimientos es, evidentemente, un momento fundamental en la programación estratégica del sitio cuyas defensas deben, obviamente, interpretar las potencialidades ofensivas y defensivas de los lugares pero, además, deben ser planificadas en función de un correcto y adecuado abastecimiento y empleo de los recursos que el contexto puede ofrecer. La práctica no es una invención del Mil Setecientos, ya que, es bien conocida y difundida ya en tiempos del mismo Antonelli, como hemos visto antes, en ocasión de la escogencia del sitio de Portobelo pero, en esta época se encuentra organizada y establecida dentro un procedimiento operativo puesto a prueba de acuerdo con los nuevos criterios que resuenan las nuevas sugestiones iluministas.

Al inicio de 1753, Sala compila la "Relación, o Descripción de la Babia y Ciudad de S. n. Phelipe de Portovelo, en la Costa del Mar del Norte de las Yndias Occidentales en el Reino de Tierra Firme. Ignacio Sala. Portobelo 25 enero 1753 "34. En la exposición de los resultados del análisis del sitio, el ingeniero reconfirma las ventajas tácticas del sitio escogido por Battista Antonelli, entre las cuales, se aprecian además de las condiciones climáticas, la amplitud contenida del ingreso de la bahía "[...]su boca solo tiene quinientas y sesenta Tuesas [...]”, la escasa profundidad del corazón de la bahía y la presencia en el entorno de altos relieves "[...] tan poblados de bosque, son absolutamente impenetrables [...]”. Junto a la "Relación", Sala elabora los proyectos para la redefinición de las defensas del sitio los cuales, ilustra en diversos dibujos detallados.

El principio que guía la reorganización es el de construir un sistema defensivo integrado en el que operen, simultáneamente, más puestos defensivos los cuales, según el eco de los preceptos de Vauban y después los adoptados de las Academias Militares, permitirían optimizar los recursos ${ }^{35}$ relacionados a la construcción de imponentes y costosas plazasfuertes. Sala dispone la realización de dos baterías nuevas, la de San Fernando en el lado septentrional del ingreso a la bahía y la de Santiago, en el lado meridional las cuales, debían cruzar los tiros al mismo tiempo contra los atacantes.

\footnotetext{
${ }^{33}$ Lilly Library Manuscript Collections; Crame Mss. Carta de O’Reilly a Don. Agustín Crame nombrado por S.M. Para el reconocimien -to de cada una de las plazas que se expresaran...7 mayo 1776; cit. en (Arcos Martínez, 2016).

34 AGI, Sevilla, sign. Panamá 356. Cit. en (Zapatero, 1985).

${ }^{35}$ En el prólogo al lector del "Tratado de las defensas de las Plazas de M. Vauban, Mariscal de Francia, con algunas reflexiones y adicio-n es" Sala escribe que "Todo el Mundo sabe, que la Fortificacion es una Ciencia, que ensena à disponer las Murallias, [...] y demás partes de u na Plaza de forma, que pocos hombres puedan defederse de muchos; por que de otra manera sería inútil el inmenso gasto [...]”
} 
Invest. pens. crit. (ISSN 1812-3864)

Vol. 5, No. 2, mayo-agosto 2017

pp. $83-109$

Con respecto al esquema de Antonelli y su sobrino Rota, se introducen algunas actualizaciones y adaptaciones que responden a la evolución de la praxis militar de la época. Tácticamente es evidente el retroceso de la ubicación de Todofierro en la nueva de San Fernando para constituir, de hecho, la reproposición de una solución a tenaza que pudiese, por un lado, vencer simultáneamente al agresor desde dos lados; y por otro, que emplease los cañones desde dos frentes distintos, lentificándole las operaciones de recarga y disponibilidad de fuego ${ }^{36}$. Con las mismas premisas se actualiza y adecúa el puesto defensivo de San Jerónimo cuyo sitio había sido ya sugerido por Cristoforo Rota para efectuar una construcción que sólo en parte había sido realizada ${ }^{37}$ y que Sala, incorpora en la nueva homónima batería.

En el "Plano particular de la Ciudad de $S^{n}$ Phelipe de Portovelo [...]" datado 25 de enero de $1753^{38}$, Sala indica en color amarillo lo correspondiente a la nueva sección a realizar, como una actualización de la misma construcción en la "4.Real Contaduria". En la didascalía explicativa, se indica la antigua construcción como "D. Red. ${ }^{\text {to }}$ o Cast antiguo de $S^{n}$ Geronimo que se debera componer" y en efecto, el color amarillo es utilizado para las cañoneras a realizar que se unen a la construcción de la "K.Bateria proiect." de la C[i]udad con su ...nto para los fines que se exp... en la relacion", también ella coherentemente con el color amarillo de las obras a ejecutarse ${ }^{39}$.

El concepto táctico de las baterías es el de realizar algunas plataformas bajas para alojar las piezas de artillería, con el frente lo más reducido posible en altura para mimetizar el fuerte y reducir el área expuesta al tiro enemigo, así como, el mismo Sala escribe en la hoja de plano fechada 25 de enero de 1753, donde se ilustra el proyecto de la Batería de San Fernando: "Elebacion (sic) del Fuerte de San Fernando con sus dos Baterias alta y baja, vista de la parte de la entrada del Puerto en que se demuestra el poco objeto, que estasFortificac." presentan a los Nabios enemigos" $"$.

El mismo concepto con dibujo a bajo perfil, se hace aún más evidente en la parte central de la batería de San Jerónimo la cual, resulta casi a ras de la superficie del agua. El objetivo es el de aprovechar esta configuración para complicar las operaciones de mira al enemigo y, al mismo tiempo, poder disparar una primera salva para desarbolar y volver ingobernable el navío agresor, disminuyendo radicalmente la peligrosidad. La importancia de la correcta disposición de las baterías es un tema central del proyecto y de su concepto táctico, así como, Sala había ya argumentado en precedencia para las soluciones a adoptar en el Fuerte de San Fernando en Cartagena.

"[...] ninguna batería de Tierra por fuerte que sea, es capaz de resistir los fuegos de un navio de guerra siempre que este le pueda presentar el costado, porque la artillería del costado de un navio de guerra regularmente es superior en el número de cañones a la de la batería terrestre [...]" y que "[...] después de haver dado la descarga de un

\footnotetext{
36 Vease nota 41.

${ }^{37}$ Antonio Fernández de Córdoba describe en 1672, la construcción como un "[...] bonete cuadrado que puede tener 40 a 50 pies de cuadro [...] esta pequenez no le permite alojamiento ni disposicion de tener guarnicion considerable [...]”. Arch. General de Indias, Sevi lla; sign. Panamá 93, cit. in (Castillero Calvo, 2016).

${ }_{38}$ Cartoteca del Centro Geográfico del Ejército, Madrid; sign. PAN 04-09.

${ }^{39}$ Para el uso de colores en los proyectos de los ingenieros del Real Cuerpo de Ingenieros en el siglo XVIII, véase (Giménez Prades, y otros, 2009).

${ }^{40}$ Cartoteca del Centro Geográfico del Ejército, Madrid; sign. Ar.J-T.4-C.4-35.
} 
Invest. pens. crit. (ISSN 1812-3864)

Vol. 5, No. 2, mayo-agosto 2017

pp. 83-109

costado, puede con facilidad revolverse y dar el otro, que da superior; a más de que como la artillería del navío con la mucha gente que contiene, está más promptamente servida que la de tierra, quedan siempre los fuegos de esta Artillería inferiores a los de un navio $[\ldots]^{41}$

Más allá de una decisión estratégica, la justificación de la realización de tres cuerpos de delgadas baterías y sus relativos anexos, en vez de, obras defensivas más corposas o de una plazafuerte equipada, puede depender de la orientación de la "defensa por indefensión” adoptada por la Corona en aquella época, hacia los territorios Americanos considerados de valor estratégico secundario, como ha sido analizado por Zapatero ${ }^{42}$ en su vasta y detallada obra.

En efecto, hacia la mitad del Mil Setecientos, Portobelo había perdido mucho de su importancia, especialmente, después de la abolición de la Feria y por los ataques de Vernon. En otras palabras, había disminuido la razón de su fundación que, en vez, se reduce y se restablece como un presidio de control de este tramo de la costa, contra el contrabando y la posible realización de asentamientos o cabezas de playas enemigos. El proceso de declinación se aprecia mayormente, si consideramos el valor de los gastos militares repartidos a los presidios militares de la costa de Tierra Firme en el curso del siglo XVIII. En un total de más de 43 millones de pesos, el 55\% es destinado a Cartagena, que viene valorizada como un centro militar de principal importancia en el área; el 24\%, a Panamá / Chagre - San Lorenzo; y sólo el $6 \%$, a Portobelo que, mas bien, ha adquirido un rol de secundaria importancia ${ }^{43}$.

Sala no logra seguir la realización completa de su obra y antes de regresar a Cartagena, le entrega a Hernández una "Ynstrucción que deberá observar el Capitán D.n Manuel Hernández Yngeniero Segundo de los Exercitos de S.M. en la construcción de las fortificaciones proyectadas y resueltas por mi en virtud de Real Orden para defender la Babia y la Ciudad de Portovelo" "44. En 1753, se inician las obras a las nuevas baterías que vienen terminadas antes de 1760, con algunas adaptaciones respecto a los dibujos originales pero, que aún así, no distorsionan el sistema global de Sala y que nacen, probablemente, más por necesidad durante la ejecución y por oportunidad constructiva surgidas en fase de realización que, por una revisión táctica del proyecto.

Entre las varias modificaciones aportadas, la más consistente se da en la Batería de Santiago. En el proyecto de Sala de $1753^{45}$ aparece una tercera porción para la artillería construida, sustancialmente, en el agua, más allá del perfil de la costa la cual, es indicada como " $V$. Proiecto para alargar esta Bat. en elbajo con 6 cañones del mismo calibre” y donde, por estar a la misma altura de la didascalía del proyecto, se podría individuar como la indicación de una propuesta de ulterior desarrollo de la obra. En la hoja de proyecto que Hernández elabora al término de los trabajos (figura 1), "Plano, y Perfil de la Bateria de Santiago finaliz" su const." en Portobelo segun se demuestra Explicacion [...] Portovelo 9 de Mayo 1760" ${ }^{46}$, se rende cuentas de la

\footnotetext{
41 Arch. General de Indias, Sevilla; sign. Santa Fe, 940. S/F,cit. in (Freire, 2013).

42 (Zapatero, 1985).

${ }^{43}$ El estudio acompañado por tablas exhaustivas está en (Álvarez, 2005).

${ }^{44}$ Arch. General de Indias, Sevilla; sign. Panamá 356, cit. in (Zapatero, 1985).

${ }^{45}$ Cartoteca del Centro Geográfico del Ejército, Madrid; sign. Ar.J-T.4-c.4-35.

${ }^{46}$ Cartoteca del Centro Geográfico del Ejército, Madrid; sign. Ar.J-T.4-C.4-36.
} 
Invest. pens. crit. (ISSN 1812-3864)

Vol. 5, No. 2, mayo-agosto 2017

pp. 83-109

construcción de la obra con dos baterías y sin la tercera, configuración que ha llegado planimétrica y consistentemente invariada hasta hoy.

Además de estas obras principales, Hernández junto a su segundo, el ingeniero extraordinario José Antonio Brist, realiza otras construcciones entre las cuales las dos "Casas-fuertes" gemelas, la cuya realización esta descrita en el "Plano, y Perfil de una de dos Casa-fuertes construidas con las mismas medidas sobre el alto $S_{-}$" Fernando la una; y sobre el Fuerte de Santiago la otra, en Portovelo, para impedir que los enemigos se apoderen de las alturas y dominen los dos Fuertes $d[i c]$ hos" ${ }^{47}$ datado en el 9 de mayo de 1760 en el que, probablemente, se retoman los planteamientos de Sala en el citado "Plano particular de la Ciudad de S"Phelipe de Portovelo [...]" donde el autor indicaba en amarillo, la edificación de "Tres Reductos o casasfuer. [...]" ${ }^{48}$.

Entre las obras adicionales efectuadas durante este período, también se aprecia un "Almazen grande de Polbora [sic]" "9, lastimosamente, demolido en los años sesenta del siglo pasado ${ }^{50}$ que, era un interesante ejemplo de replanteamiento de la tipología de este tipo de construcción y que ha sido documentado en las referencias tratadísticas de la época.

En 1779, El Visitador Brigadier don Agustín Crame, se encuentra en Portobelo donde inspecciona el área que juzga adecuada según los parámetros técnicos tácticos de la época: el sitio completo viene considerado como protegido, ya que, está circundado por un conjunto integrado de defensas naturales como lo son los relieves y la densa vegetación, y que se componen con los artificiales como las obras defensivas que, además, las considera suficientes. En el "Plano de Portovelo" ${ }^{51}$ con fecha del 27 de enero de 1779, señala como única integración, una nueva obra defensiva que indica como "Campo proyectado en la Cumbre con-tra la avenida de los enemigos p. 'el V alle de Honduras" con la cual, ir a reforzar el perímetro Sur presidiando la cima de los relieves sobre el poblado.

\subsection{San Lorenzo}

El estado actual del Fuerte de San Lorenzo en la Boca del Chagre después del ataque de Vernon está documentado en los levantamientos métricos efectuados por el Ingeniero Nicolás Rodríguez, entre ellos, el "Plano De la Boca del Rio de Chagre, en la Costa del Mar del Norte de la America Septentrional en el R." de

\footnotetext{
${ }^{47}$ Cartoteca del Centro Geográfico del Ejército, Madrid; sign. Ar.J-T.4-C.4-39.

${ }^{48}$ En el dibujo se encuentra una laguna que deja incompleta la frase "Tres Reductos o casasfuer.s para asegu[rar] ...”.

49 "Plano de Almazen de la Polbora à media legua de la Ciudad de Portovelo capaz de 800qq" de Polbora en tarras, que esta finaliz: con dos Garitones en la cerca / Fecha 9 de Mayo de 1760 / Manuel Hernandez. ". Cartoteca del Archivo General Militar de Madrid, sign. A r.J-T.4-C.4-38.

50 (Castillero Calvo, 2016).

${ }^{51}$ Cartoteca del Archivo General Militar de Madrid, Madrid; sign. PAN 03/10.
} 
Invest. pens. crit. (ISSN 1812-3864)

Vol. 5, No. 2, mayo-agosto 2017

pp. 83-109

Tierra Firme con demostraciòn del Castillo S." Lorenzo el Real, y su Bateria baja demolido por la Nación Inglesa en el Año $1740 "{ }^{52}$ datado en el año 1749 y que sigue a uno precedente con fecha del $1744^{53}$.

En el extremo occidental del promontorio, se representa lo que resta de la construcción establecida por Battista Antonelli a finales del Mil Quinientos, con las sucesivas modificaciones y adaptaciones ${ }^{54}$ " $A$. Castillo di S." Lorenzo el Real demolido / B. Bateria baja demolida / C. Fosso [sic] del Castillo". En el lado oriental, en cambio, se indica "D. Obra exterior que se principiò en los años pasados para extencion del Castillo" que corresponde a un perfil a tenaza compuesto por una cortina flanqueada por dos baluartes en el exterior del cual, corre un foso atravesado por "E. Puente de Comunic." para el Pueblo". Esta es la configuración al neto de algunas reparaciones y obras de menor entidad ${ }^{55}$ que encuentra el ingeniero Hernández cuando llega a San Lorenzo en 1761.

En el "Plano del proyecto de Chagres / formado en el año de 1763" "56 redactado por el mismo Hernández, se delinean las piedras angulares del proyecto como será inmediatamente realizado. Las obras de Antonelli y Rota son definitivamente archivadas, eliminando los restos de la Batería Baja, incorporando la to-rre y enterrando la tenaza/hornabeque en el lado frontal de tierra y reportando todo el nivel de piso de la nueva fortificación a una cuota homogénea más alta. En el lado occidental frente mar, se realiza un único parapeto bajo, básicamente, una batería con merlones para alojar los cañones y atacar a los adversarios provenientes del mar. El lado septentrional, en cambio, se cierra volviendo a considerar algunos puntos de la situación de las obras precedentes que había documentado Rodríguez, así como, el frente este donde es retomado y mejorado el trazado de la tenaza que protegía el frente de tierra.

La novedad mayor parece ser el proyecto de la nueva "Bateria exterior" que constituye un cuerpo delantero separado del Castillo y que habría debido amplificar las posibilidades defensivas y ofensivas en áreas que no se podían cubrir directamente. Ya ha sido señalado ${ }^{57}$ que esta batería es muy similar en su diseño planimétrico y concepción a la de Santiago de Portobelo, al indicar la actitud de los ingenieros militares del Real Cuerpo derivada por la formación en las Academias Reales, al utilizar el repertorio de soluciones técnicas pre - elaboradas que readaptaban a los sitios según las especificaciones de éstos.

Hernández supervisará la construcción de San Lorenzo de 1761 a 1768, año en el que se declara que ha sido "planteada toda la Fortificaciòn de la plaza". Más adelante, entre enero y febrero de 1779, El Visitador, Brigadier don Agustín Crame, se encuentra en San Lorenzo para su inspección. En su reporte, destaca

\footnotetext{
52 Real Biblioteca Palacio Real Madrid, sign. II/1622.-- | f. 41-43 (1).

53 "Plano de la Boca del Río Chagre, en la Costa del mar del Norte del Reyno de Tierra Firme. Con demostracion del castillo San Lorenzo el R ealy su bateria baja que en la Punta Septentrional de dha. boca demolieron los ingleses en esta presente guerra, el año pasado de 1740 [sic] / Le bantado y Hecho por el Cap. D. NicolasRodriguez, Ingeno. Ordino. por S.M. del Rno. de Tierra firme [sic]. "Editorial 1745. Cartoteca del Archivo General Militar de Madrid, sign. PAN 5/10

${ }^{54}$ En relación a los asuntos constructivos anteriores al período en estudio, véase (Zapatero, 1985), (Sartor, 2004) y (Castillero Calvo, 2016).

55 El presidente de la Audiencia de Panamá, gobernador y comandante de Tierra Firme, Dionisio de Alcedo y Herrera encarga al ingeniero ordinario Nicolás Rodríguez de proceder a las mediciones del Fuerte de San Lorenzo y de realizar las reparaciones indispensables entre 1744 y 1749. (Castillero Calvo, 2016).

${ }^{56}$ Cartoteca del Archivo General Militar de Madrid; sign. PAN-5/12.

57 (Zapatero, 1985).
} 
Invest. pens. crit. (ISSN 1812-3864)

Vol. 5, No. 2, mayo-agosto 2017

pp. 83-109

la importancia de la Fortaleza por su rol de defensa de acceso hacia la ciudad de Panamá del cual, su ingreso por el lado del Caribe podía realizarse fácilmente sólo si se navegaba por el Chagres.

La Fortaleza no recibe un juicio positivo. Primeramente, es definida como una "fortaleza cerrada", en otras palabras, una fortaleza que en caso de ataque resultaba difícil de defender y socorrer, además de, estar circundada por relieves desde donde podía ser atacada. Según Crame, la Fortaleza es sólo una obra difensiva y no difensiva-offensiva como, en cambio, habría sido conveniente que fuera. Esto, debido a que no lograba cubrir y presidiar todas las áreas limítrofes, especialmente, a las ensenadas del Norte como el Portete de Batata, que podía ser fácilmente usado por el enemigo para un desembarque sin ser detectado.

Otra crítica va dirigida a la batería con perfil circular ubicada adelante del hornabeque, que por su forma concebida exactamente opuesta a la de tenaza que debía proteger, no permitía un válido presidio del foso, "[...] la bateria Circular [...] sin estar visto ni difendido su foso de parte alguna del recinto, circunstancia que la hace sumamente defectuosa, y lo mas particular es que teniendo este mismo defecto la bateria alta y avanzada $M$. que se esta demoliendo, se ha trasvadido, con gastos muy crecidos, en corregir el primer yerro, con otro mayor" 58 . A pesar de esto, Crame considera todavía aceptables las partes restantes de la guarnición y con espíritu práctico y concreto, juzga económicamente más ventajoso, el mantener la luneta circular y la batería avanzada que, de todos modos, ofrecían un grado de protección, en vez de, realizar un proyecto nuevo y más costoso.

Como única corrección táctica propone la realización de dos baterías sobre los relieves ubicados más allá de la caleta del frente norte, para vigilar aquellas ensenadas que habían quedado peligrosamente sin presidio. En el informe que elabora, adjunta un plano detallado (figura 3) con las oportunas secciones ${ }^{59}$ fechado en 1779, donde se aprecia que aún quedan algunos trabajos por completar, así como, se indica en la leyenda y con el color amarillo de algunos particulares. En especial, se observa que deben ser completadas algunas estructuras como las "F. Bovedas construidas hasta el arranque" correspondientes a los locales en el lado interno del hornabeque; mientras que, han sido concluidas las del frente sur "E. Bovedas a prueva [sic]concluidas". Dada la magnitud de las estructuras a construirse y, además, establecidas en un punto estratégico del complejo defensivo, cabe preguntarse si en esta época la Fortaleza era real-mente operativa al máximo de sus posibilidades.

Otro elemento por completar, aparentemente, de menor importancia pero, como enseñado en las Academias, de importancia extrema, era la reserva del agua "G. Estanque de aguaque deve [sic]cubrirse para aljive [sic]". En la leyenda, se indican las funciones tácticas de las nuevas baterías que Crame prevé realizar "R. Bateria de 6 cañones de à 16 proyectada en la loma dominante el Portete de Batata para estenuar [?] el desem. "e "S. Bateria de 3 cañones en el fondo de la Cañada q. deven [sic]estar encavilatos [?] hasta el momento precisso [sic] del desembarque".

Otra indicación estratégica, valiosa para delinear el contorno técnico de la obra y los conocimientos del autor, es la anotación referente a un levantamiento ubicado detrás de las baterías en cuestión, "L. Loma

58 "Plan de defensa para el Castillo de S.Lorenzo de Chagre hecho de orden del Rey por D. Augustin Crame [...] 9 Feb. ${ }^{\circ} 1779$ [...]" ya en Serv. Hist. Mil. De Madrid; sign. 6.708: 5-2-9-1.1.

59 Cartoteca del Centro Geográfico del Ejército; sign. J-4-4a-41. 
Invest. pens. crit. (ISSN 1812-3864)

Vol. 5, No. 2, mayo-agosto 2017

pp. 83-109

a nivel con esta difencia [sic] [es decir, las baterías de R. y S.] con el Castillo y su [?] immediato à la qual [sic] no pueden conducir Artilleria los enemigos, no desembarcandola en el Portete de Batata”. En relación, a la Batería avanzada, se anota "M. Bateria avanzada cuya demolicion se juzga conveniente suspender [?] por [?] el excesivo gasto de 30 mil varas cubicas de excavacion en la peña, como por lograr con sus fuegos descubrir la Cañadas immediatas [sic]; la extensión de esta batería debe [sic] reducirse [...] para no prestar proporcionado alojamento a los enemigos en casso [sic] de perderse [?] y tambien tiene la ventaja de que en la parte O que esta mas baja que lo restante de la Bateria habrá dos Cañones, que no pueden ser descubiertos [sic] ni batidos de la loma L".

Para conectar la Fortaleza con la Batería, al puesto del recorrido excavado en trinchera previsto inicialmente por Hernández y que repetía la solución adoptada en Portobelo para unir las dos Baterías de San Fernando, Crame propone un percurso externo a cuota de campaña, flanqueada solo por un muro de protección al Norte. El trabajo de Crame será examinado por la "Junta de Fortificacion y Defensa de Yndias" sólo hasta 1786 la cual, se exprime para dejar la situación, sustancialmente, invariada, sin ninguna responsabilidad ni compromiso para las finanzas de la Corona, permitiendo la realización de las dos nuevas Baterías propuestas con estructuras provisionales e invitando a no realizar siquiera "lasbovedas a prueba", ya que, se consideraban útiles solamente donde el enemigo ponía sitios por un largo tiempo, situación que no se prevee por el San Lorenzo. En general, se considera que "[...]el Castillo sin embargo de sus defectos debe mantenerse en la forma que hoy se halla, y que ès capaz. de buena defensa si se sabe sacar partido de las ventajas de su situacion [...]" ${ }^{00}$. El cuadro geopolítico, a estas alturas, ha cambiado y el Castillo de San Lorenzo el Real de Chagre no cuenta más con la importancia estratégica del pasado.

\section{Reflexión Comparativa entre las Fortificaciones de los siglos XVI - XVII y del siglo XVIII. E1 contexto y la metodología}

Basándonos en los análisis realizados, se hace interesante proponer una reflexión comparativa sobre los diversos contextos que constituyen el fondo de la realización de las fortificaciones efectuadas a finales del Mil Quinientos y de aquéllas de la segunda mitad del Mil Setecientos en Portobelo y la Boca del Chagre, partiendo desde la consideración que, por lo general, una construcción así como es edificada, no es sólo la transposición en obra de un dibujo sino, el producto de una serie de factores al contorno que se entrelazan y que, muy a menudo, se apartan del alcance concluido en la obra.

En primer lugar, se debe comenzar por reconocer que extisten importantes diferencias de contexto que han influenciado directamente la realización y la operatividad de las fortificaciones en las dos épocas. Las obras proyectadas por Battista Antonelli, en específico, el Castillo de San Felipe o Todofierro, el Castillo de Santiago de la Gloria o la Torre con Plataforma en la Boca del Chagres; a lo largo del tiempo de su empleo operativo, concluido esencialmente en poco menos de un siglo y medio desde su realización

60 "Papeles sobre la defensa de Porto-Belo, Chagre, y Panamà- Madrid 9 de Mayo de 1786"; ya en Serv. Hist. Mil. De Madrid; sign. 6.7 10: 5-2-10-5. 
Invest. pens. crit. (ISSN 1812-3864)

Vol. 5, No. 2, mayo-agosto 2017

pp. $83-109$

hasta los últimos ataques de Vernon, atraviesan un contexto local de situaciones complejas y de asentamiento dinámico en los cuales, además de la presente y efectiva amenaza enemiga inglés, existe todavía por completar y terminar de registrar la presencia en el territorio y encontrar también los mejores equilibrios de los mismos asentamientos, como se aprecia en las situaciones de Portobelo. El período sucesivo cuando serán operativas las Baterías Alta y Baja de San Fernando, de Santiago, de San Jerónimo y el Castillo de San Lorenzo de la Batería Avanzada y de la Luneta, habrá un carácter a nivel local más estático, donde muchas de las urgencias y de las presiones del período precedente serán menores.

En un ámbito más amplio, debemos considerar la evolución del cuadro estratégico y geopolítico del área del Caribe en las diversas épocas. Las condiciones que existen cuando Antonelli elabora el "primer Plano de Defensa" y el sobrino Rota supervisa las obras, como hemos dicho, no son las mismas de la época de Sala, Hernández y Crame y de aquélla inmediatamente posterior, donde las fortificaciones de Portobelo y sobretodo, de la Boca del Chagre, han progresivamente disminuido a un rol de presidio con un horizonte siempre más local con respecto al pasado, condiciones que llevan a requerir obras defensivas de menor consistencia con respecto a aquéllas de finales del Mil Quinientos o a aquellas contemporáneas de una plazafuerte de primera importancia como Cartagena. Es evidente que las nuevas Baterías de San Fernando, Santiago y San Jerónimo, por cuanto inspiradas en los más modernos cánones de la ingeniería militar, no cuentan con la misma función de guarnición en caso de ataque prolungado que desempeñaban, o así habrían debido, las Fortalezas de Todofierro y sobretodo, de Santiago de la Gloria. La situación de San Lorenzo es ligeramente diversa con una efectiva evolución de la consistencia de la obra fortificada que se manifiesta a través de una racionalización de las preexistentes y la corrección de algunas vulnerabilidades. Todavía, incluso en este caso, se da una disminución del rol estratégico del presidio de los cuales, son prueba las observaciones antes expuestas por la Junta de Fortificación y Defensa de Yndias.

Otra consideración, se refiere a la eficacia real de las soluciones adoptadas en las operaciones bélicas, evaluación que es posible, sólo para las fortificaciones realizadas a finales del Mil Quinientos y no para aquéllas de la segunda mitad de Mil Setecientos que nunca tuvieron un real "collaudo" operativo en guerra. En cuanto a las primeras, a pesar de esto, se pueden hacer algunas consideraciones que permiten entender que la justificación de las derrotas sufridas contra los ingleses recaen no solamente en un tal vez otro modo enfatizado en un mal proyecto, tanto también, en una serie de otros factores que han tenido un peso no transcurable. Por una parte, en efecto, existen condiciones de partida que influencian la ideación y la construcción de las obras, ya que, los presidios que establece Antonelli son proyectados y realizados con carácter de urgente necesidad para poner en seguridad un vastísimo territorio, por otro, no completamente conocido todavía. El percurso constructivo que resulta es complejo y plagado de adecuaciones y remodelaciones no siempre, coherentes. Por otra parte, es evidente y documentado el mal estado de gestión de los presidios, con falta de mantención, aspecto no insignificante en un contexto ambiental como el de Portobelo y la Boca del Chagre a los cuales, se suman las condiciones no óptimas de los armamentos y de las mismas guarniciones militares que se alternaban en los presidios. Sobre esta situación es revelador el reporte de Jorge Juan y Antonio de Ulloa en las "Noticiassecretas de America", la relación confidencial para el Rey, del 1747, sobre el estado de las Colonias Americanas: 
Invest. pens. crit. (ISSN 1812-3864)

Vol. 5, No. 2, mayo-agosto 2017

pp. 83-109

"[...] estas fortalezas [San Felipe, también llamado Todofierro, el Castillo de Santiago de la Gloria y el antiguo San Jerónimo] fueron arruinadas y demolidas por el almirante Vernon en el año 1740, cuando se apoderó de este puerto con una crecida armada, logrando este trofeo, no tanto porque fuese regularmente facil rendirlo, como por haberlo hallado sin prevencion. La mayor parte de su artillería estaba desmontada, y con particularidad la del castillo, de todo calibre, donde lo estaba casi toda por falta de cureñas. Las municiones de guerra eran muy pocas y malas; su guarnicion tan corta, que ni aun se hallaba completa la que le estaba asignada en tiempo de paz. [...]" " [...]La fortaleza de Chagres tiene una situacion admirable por estar fundada sobre un alto peñasco escarpado acia la mar, desde donde domina el fondeadero preciso de las embarcaciones grandes, y cubre con sus fuegos por otra parte la entrada del rio. Esta no se hallaba en mejor estado que la de Portobelo En quanto á cureñas, municiones y otras providencias Chagres no se diferenciaba de Portobelo, no hallándose uno ni otro en estado de hacer mas defensa que la de empezar á resistir y luego rendirse por necesidad, porque les faltaba todo lo preciso para hacer otra cosa, y en semejantes circunstancias es de poca ó ninguna entidad la fortaleza del terreno [...]" "[...]Los Ingleses estaban tan puntualmente informados del estado en que se hallaban aquellas plazas del Mar del Norte que no ignoraban su debilidad, ni lo distante de los recursos para recibir los socorros: todo lo tenian tan prolijamente examinado, que no se les ocultaba nada de lo que alli pasaba [...] "61

Y todavía es necesario considerar que los territorios donde llega Antonelli aún están en curso de exploración y la colonización no se ha todavía completado. Esta situación se traduce en lo específico en fuertes dificultades logísticas sea para la investigación y adquisición de materiales, sea por la obtención de las maestranzas con experiencia adecuada para las realizaciones de obras de tal importancia. Obviamente, estas dificultades además de, determinar el aumento de los costos y de los tiempos de realización, con la erosión consecutiva del presupuesto disponible, determinan una ejecución no óptima de las obras, circunstancia tanto más grave, ya que, constituirá un verdadero y propio defecto genético de las fortalezas que las sucesivas y no siempre coherentes obras de adecuación, no lograrán jamás a remediar completamente. En este sentido, la obra de los ingenieros del Real Cuerpo tiene el mérito o tal vez, para mayor precisión, la oportunidad, de eludir a este círculo vicioso y de proceder con un nuevo planteamiento y un nuevo proyecto, con la parcial excepción de San Lorenzo.

En relación, a las dificultades ejecutivas emerge otra cuestión. Hemos ya observado que se repite cíclicamente el leitmotiv de la necesidad de intervenir en las fortificaciones con solicitudes que no son respondidas plenamente o que encuentran éxito en empresas mal manejadas y fuertemente contraproducentes ${ }^{62}$. Entre las varias causas a la base de esta situación que, evidentemente, se entrechan íntimamente con los asuntos histórico - económicos de España, está también la naturaleza misma de la cadena decisional que encabeza a la Metrópolis, donde las necesidades urgentes locales del Istmo chocan con situaciones consideradas estratégicamente más importantes o son resueltas con correctivos y contra observaciones no siempre adecuadas a la realidad contingente de los lugares o, simplemente, a causa de la distancia, vienen

\footnotetext{
${ }^{61}$ (Ulloa, y otros, 1826).

${ }^{62}$ Un ejemplo de esta última situación, paradigma del mal empleo de los recursos, es el proyecto incompleto de trasladar el poblado de Portobelo al adyacente recinto amurallado de San Carlos, cuyo fracaso asume un contorno todavía más relevante si pensamos que había sido ideado y autorizado precisamente para resolver todas las problemáticas defensivas del pobla-d o.
} 
examinadas mas bien con retraso. Esta separación de las necesidades contingentes del territorio unido al desplazamiento temporal entre el envío de la petición, su examen y elaboración de una solución, además no siempre en línea con cuanto es necesario y solicitado, se revela en alguna situación perjudicial y causa pesadas consecuencias que hemos visto. Así como observado, todavía en la segunda mitad del Mil Setecientos deben pasar siete antes que la Junta de Fortificacion y Defensa de Yndias examinen las plantas y las relaciones de Crame.

Para encuadrar el contexto realizativo de las fortificaciones de la segunda mitad del Mil Setecientos es oportuno examinar, además del contexto, también lo realizado por los ingenieros del Real Cuerpo de Ingenieros, con sus peculiares elementos característicos. La presencia misma en el escenario de este Cuerpo militar, específicamente, constituido y formado para construir las infraestructuras que la Corona necesita para gobernar, administrar y defender sus dominios es de por sí, un aspecto relevante. Con respecto al pasado donde los diversos grupos de ingenieros y hombres de armas habían resuelto no pocas veces en manera deshomogénea y contradictoria las diversas emergencias, a veces según inclinaciones personalísticas, lo realizado por Rodríguez, Sala, Hernández, Brist y Crame, al neto de las innegables diferencias y de las singulares capacidades personales, sigue un método operativo común y coherente según un percurso de continuidad propio de la línea operativa del Real Cuerpo de Ingenieros.

Precisamente, el enfoque metódico con el cual, los ingenieros afrontaron las obras a realizar resulta un elemento característico, además, significativamente permeable a las nuevas instancias iluministas que inevitablemente se tomaron el Cuerpo Militar formado sobre una base científica. Los mismos dibujos de los proyectos reflejan esta orientación, iniciando por el código representativamente común de colores, escalas métricas e impaginación que los vuelve fácilmente comprensibles e interpretables al interior del Cuerpo entre los diversos ingenieros. Las valiosas hojas de proyectos elaboradas por Sala, Hernández o Crame, no son sólo expresiones artísticas a fin de sí mismas hechas por excelentes proyectistas sino, testimonios potentes de un nuevo modo de organizar y ordenar la materia, según cánones pre-establecidos y colaudados para permitir una fácil comparación, interpretación y comunicación.

Precisamente, la formación común impartida en las Academias Militares y la integración en un único organismo con sus reglas y metodologías operativas, asegura que los ingenieros puedan ser complementarios y que puedan intersectar su propia obra, los unos con los otros, según un común enfoque metodológico y visión de las problemáticas que, a pesar, no significa un aplanamiento servil sobre una repetición acrítica de un repertorio preconstituido de los modelos. En confirmación de esto, es necesario evidenciar precisamente la ductilidad que estos ingenieros logran a demostrar en la proyectación de las obras de Portobelo y San Lorenzo y en particular, Hernández. Si, en efecto, con la Batería de San Fernando y de Santiago se realizan obras completamente nuevas, liberadas del acondicionamiento de las estructuras existentes, con una adaptación al sitio de los modelos de repertorio, ya en San Jerónimo y mucho más evidente en San Lorenzo, la necesidad de estar de acuerdo con el existente estimula un enfoque proyectual más complejo que lleva a una interesante combinación y adaptación de nuevas soluciones sobre instalaciones precedentes. 
Invest. pens. crit. (ISSN 1812-3864)

Vol. 5, No. 2, mayo-agosto 2017

pp. $83-109$

\section{Conclusiones}

Las obras defensivas construidas en Portobelo y en la Boca del Chagres durante la segunda mitad del Mil Setecientos, representan indudablemente un interesante testimonio histórico y arquitectónico de su época.

Además del mero dato cuantitativo de la consistencia, de por sí, notable y que le coloca por derecho entre los mayores complejos fortificados de la Región, en esta ocasión, queremos remarcar los otros motivos que constituyen la importancia y el valor.

Las fortificaciones del Mil Setecientos de Portobelo y de la Boca del Chagre, como las precedentes en relación a sus propias épocas, representan un claro ejemplo de la circulación y aplicación del saber, en este caso en el tema de las fortificaciones, que desde Europa viene transferido y adaptado a las condiciones particulares y específicas de las Colonias Americanas representadas, en este caso, por la costa caribeña del Istmo.

Las fortificaciones son testimonio de la obra del Real Cuerpo de Ingenieros cuyo particular campo de acción, no se agota sólo en los temas militares que son objeto de este artículo, sino que se amplía a la realización de campañas fundamentales de levantamiento topográfico y de ordenamiento infraestructural, incluyendo empresas de orden más puramente civiles que contribuyen de manera sustancial a la organización y al funcionamiento del vastísimo territorio americano.

\section{Agradecimientos}

Financiado por Universidad Católica Santa María la Antigua (USMA) a través de la Convocatoria para Proyectos de I+D 2015-2106, del Programa de Estímulo a la I+D, como parte del proyecto de investigación titulado "Plan de Estrategias para la Protección y Conservación de los Fuertes de Portobelo y San Lorenzo" (SRUI-CPEI-ID-2015-2016-010).

Colaboración para la Dirección Nacional de Patrimonio Histórico del Instituto Nacional de Cultura de Panamá y el Patronato de Portobelo y San Lorenzo. 
Invest. pens. crit. (ISSN 1812-3864)

Vol. 5, No. 2, mayo-agosto 2017

pp. 83-109

\section{Imágenes}

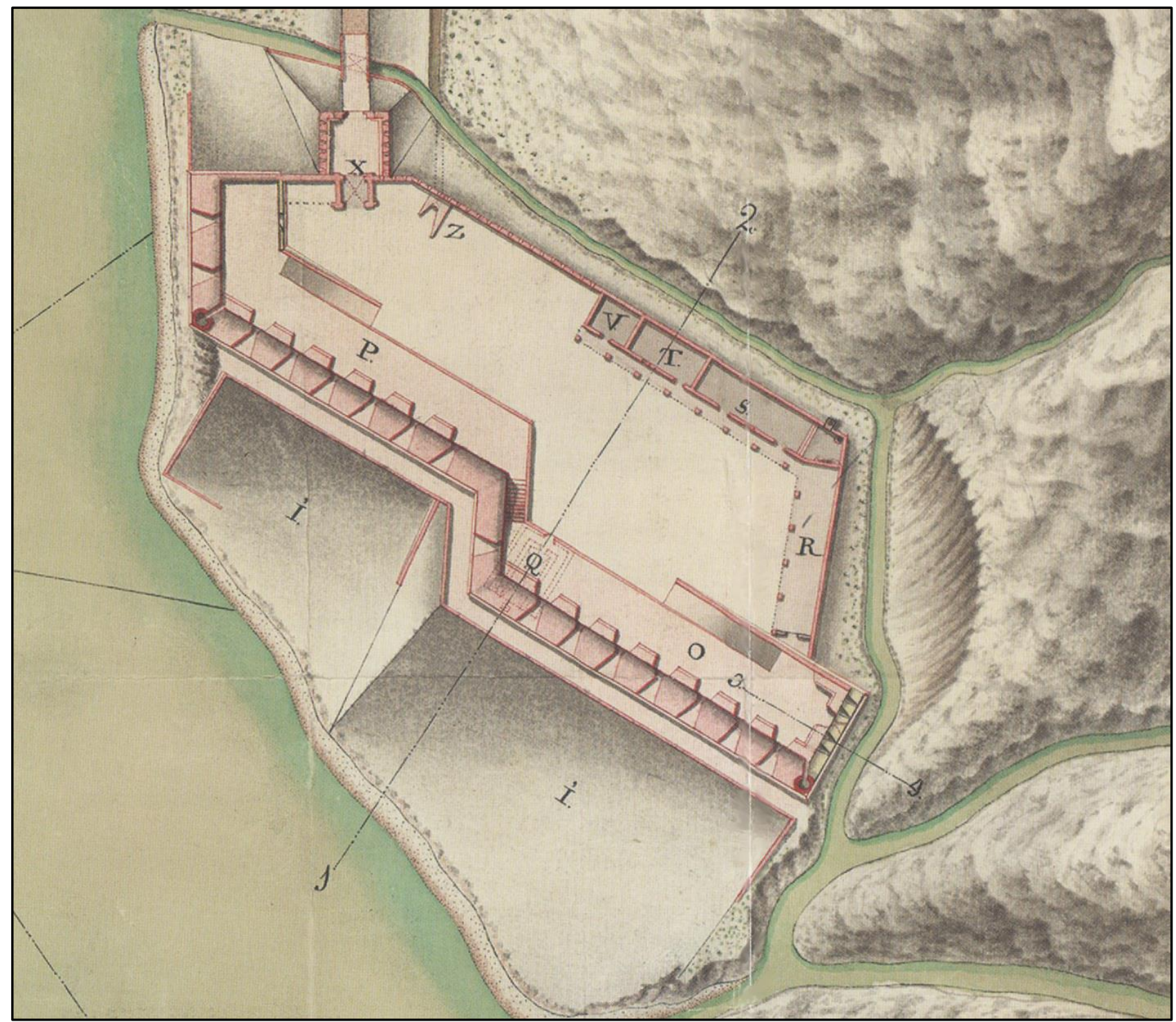

Figura 1. Particular del "Plano, y Perfil de la Bateria de Santiago finaliz." su const." en Portobelo segun se demuestra Explicacion [...] Portovelo 9 de Mayo 1760”, por Manuel Hernández. Cartoteca del Centro Geográfico del Ejército, Madrid; sign. Ar.J-T.4-C.4-36. 
Invest. pens. crit. (ISSN 1812-3864)

Vol. 5, No. 2, mayo-agosto 2017

pp. 83-109

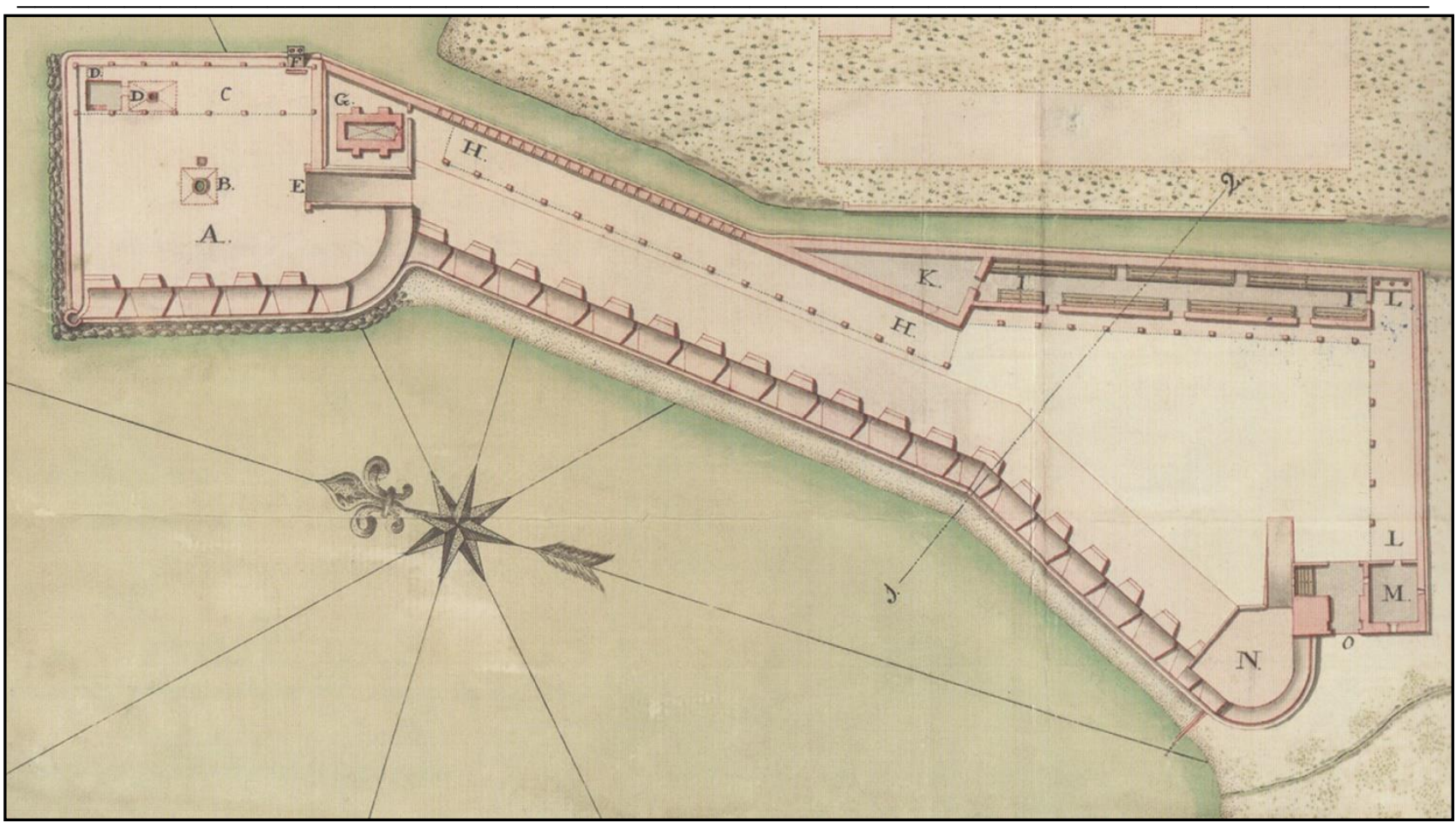

Figura 2. Particular del "Plano de la Batería de S". Geronimo en la Ciudad de Portovelo : que se halla finalizada según se demuestra en el, y su Perfil [...]Portobelo à 3 de Mayo 1760”, por Manuel Hernández. Cartoteca del Centro Geográfico del Ejército, Madrid; sign. Ar.J-T.4-C.4-37.

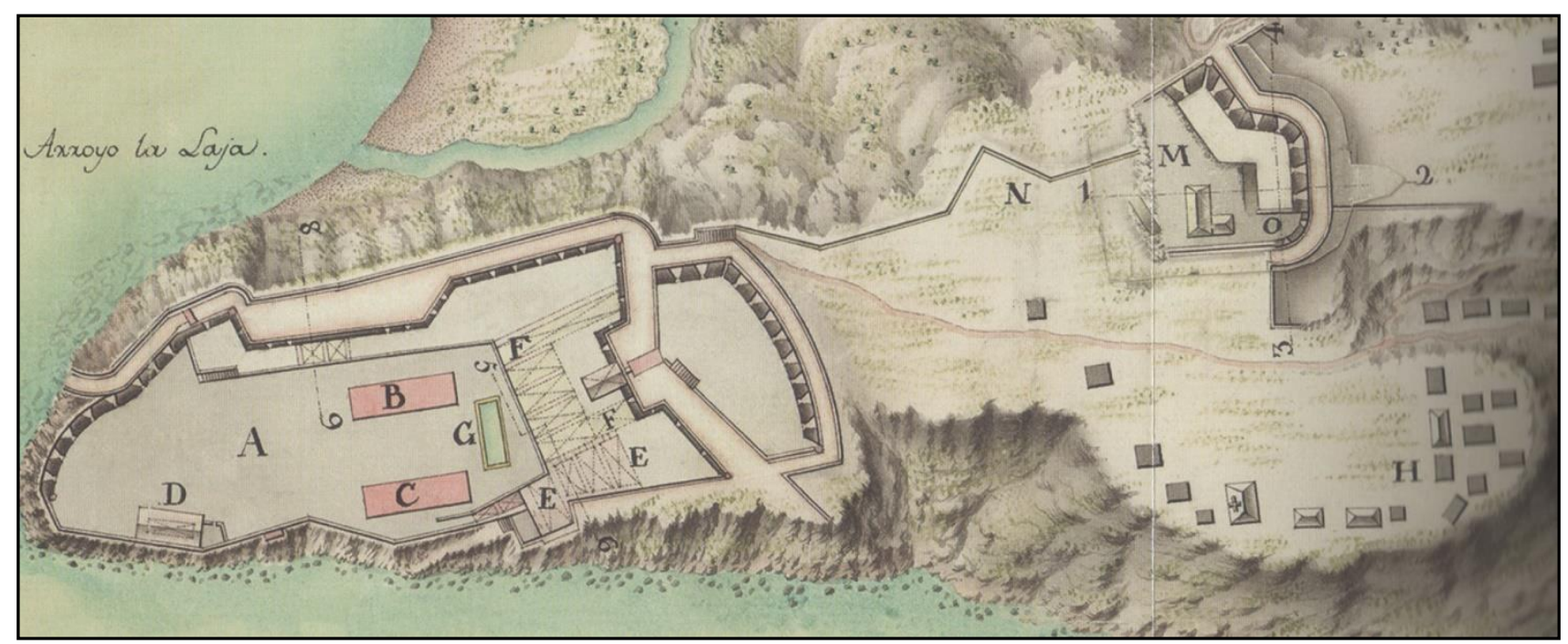

Figura 3. Particular del "Plan de defensa para el Castillo de S.Lorenzo de Chagre hecho de orden del Rey por D. Augustin Crame [...] 9 Feb.o 1779 [...]”. Cartoteca del Centro Geográfico del Ejército; sign. J-4-4a-41. 
Invest. pens. crit. (ISSN 1812-3864)

Vol. 5, No. 2, mayo-agosto 2017

pp. 83-109

\section{Bibliografía}

AA.VV. 2004. Documentos diversos del Real Cuerpo de Ingenieros. Los Ingenieros del Rey. [En línea] 2004. http://altorres.synology.me/.

AA.VV. 1997. Fortificaciones del Caribe, Memorias de la reunión de expertos, Cartagena de Indias, julio-agosto 1996. Cartagena de Indias : Instituto Colombiano de Cultura, 1997.

AA.VV. 1983. Los Ingenieros militares en España. siglo XVIII: repertorio biográfico e inventario de su labor científica y espacial. Barcelona : Universitat de Barcelona, 1983.

Álvarez, José Manuel Serrano. 2005. La Gobernacion de Cartagena de Indias y el sistema defensivo indiano en el siglo XVIII. Revista de Historia Militar. Madrid : Ministerio de Defensa, 2005.

Arcos Martínez, Nelly. 2016. Territorio y fortificación del Caribe: Agustín Crame, visitador de plazas 1777-1779. Biblio3W, Revista Bibliografica de Geografia y Ciencias Sociales. Barcelona: Universidad de Barcelona, 2016.

Cámara Muñoz, Alicia y Revuelta Pol, Bernardo. 2015. Ingeniería de la Ilustración. Madrid : Fundación Juanelo Turriano, 2015.

Cámara Muñoz, Alicia. 2016. El dibujante ingeniero al servicio de la monarquía hispánica. Siglos XVI-XVIII. Madrid : Fundación Juanelo Turriano, 2016.

Capel, Horacio, Joan-Eugeni Sánchez y Omar Moncada. 1988. De Palas a Minerva: la formación cientifica y la estructura institucional de los ingenieros militares en el siglo XVIII. Madrid : CSIC, 1988.

Casini, Leonardo y Cid, Patricia. 2016. Estudio de las fortificaciones italianas de época moderna. El retro tierra cultural de los ingenieros militares Antonelli, activos en Panamá. Investigacion y Piensamento Critico, Vol.4, No.3, Septiembre - Diciembre 2016. Panamá : Universidad Santa Maria la Antigua, 2016.

Castillero Calvo, Alfredo. 2016. Portobello y el San Lorenzo del Chagres. Perspectivas imperiales, siglos XVI XIX. Panamà : Editora Novo Art S.A., 2016.

Cutillas, Pedro Martínez. 2006. Panamá Colonial. Historia e Imagen. Madrid : Ediciones Balboa (Panamá) y Ediciones San Marcos (Madrid), 2006.

Freire, Pedro Cruz. 2013. El ingeniero militar Ignacio Sala, gobernador y comandante general de Cartagena de Indias. Noticias de su pase a indias y de su labor en las defensas de la ciudad. Laboratorio de Arte. 2013, 25.

García, Adolfo Arbelo. 2003. Milicia, fortificaciones y vida cotidiana en la Isla de La Palma durante el setecientos: una visión socio-política a través de la correspondencia privada (1764-1767). Revista de bistoria canaria. San Cristóbal de La Laguna : Universidad de La Laguna, 2003.

Giménez Prades, María, San Andrés Moya, Margarita y de la Roja, José Manuel. 2009. El color y su significado en los documentos cartográficos del Cuerpo de Ingenieros Militares del siglo XVIII. Geconservación. s.l. : Grupo Español del International Institute for Conservation - GEIIC, 2009.

Gutiérrez Escudero, Antonio. 1985. Puertos y Fortificaciones en America y Filipinas. [aut. libro] AA.VV. La defensa y las fortificaciones del Caribe español durante la época colonial. Madrid: CEHOPU, 1985.

Gutiérrez, Ramón. 2005. Fortificaciones en Hiberoamèrica. Madrid : El Viso, 2005.

Gutiérrez, Ramón. 2012. Los Ingenieros Militares en América del Sur en el siglo XVIII. Actas IV Congreso de Castellologia. Madrid : Asociación Española de Amigo de los Castillos, 2012. 
Invest. pens. crit. (ISSN 1812-3864)

Vol. 5, No. 2, mayo-agosto 2017

pp. 83-109

Llanuro y Amirola, Eugenio y Ceán-Bermúdez, Juan Agustin. 1829. Noticias de los arquitectos y arquitectura de España desde su restauración. Madrid : Imprenta Real, 1829.

Melià, Juan Tous. 2014. Gran Canaria a través de la cartografía [1507-1899] - Atlas Histórico - geográfico de la isla. San Cristóbal de La Laguna : s.n., 2014.

Muñoz Corbalán, Juan Miguel. 2015. Jorge Próspero Verboom, ingeniero militar flamenco de la Monarquía Hispánica. Madrid : Fundación Juanelo Turriano, 2015.

Muñoz Corbalán, Juan Miguel n. 2015. La profesión del ingeniero en la Ilustración. En Muñoz, Alicia Cámara y Revuelta Pol, Bernardo. Ingeniería de la Ilustración. Segovia : Fundación Juanelo Turriano, 2015.

Piñeiro, Mariano Esteban. 2002. Las academias técnicas en la España del siglo XVI. Quaderns d'bistòria de l'enginyeria, Vol. 5. Valladolid : Universidad de Valladolid, 2002.

Sartor, Mauro. 2004. Omaggio agli Antonelli, considerazioni intorno a tre generazioni di architetti militari italiani attivi nel Mediterraneo e in Italia. Omaggio agli Antonelli. Udine : Forum, 2004.

Ulloa, Antonio y Juan, Jorge. 1826. Noticias secretas de América sobre el estado naval, militar, y político de los reynos del Perú, y provincias de Quito, costas de Nueva Granada y Chile [...] sacadas á luz por Don David Barry. Londres : Imprenta de R. Taylor, 1826.

Zapatero, Juan Manuel. 1985. Dos ejemplos de fortificaciones españolas en la exposición de puertos y fortificaciones en América y Filipinas. Madrid : CEHOPU, 1985.

Zapatero, Juan Manuel. 1985. Historia del Castillo San Lorenzo el Real de Chagre. Madrid : Ministerio de Defensa, Servicio Historico Militar ; Ministerio de Obras Publicas y Urbanismo, CEHOPU, 1985.

Zapatero, Juan Manuel. 1985. La Escuela de Fortificaciòn Hispanoamericana. Puertos y Fortificaciones en America y Filipinas. Madrid : CEHOPU, 1985. 